\title{
Sumberdaya Alam Lithium Indonesia
}

\author{
Salafudin ${ }^{1}$ \\ ${ }^{1}$ Institut Teknologi Nasional, Bandung, Indonesia \\ Email: salafudin@itenas.ac.id ${ }^{1}$ \\ Received 07 Desember 2020| Revised 08 April $2021 \mid$ Accepted 13 April 2021

\begin{abstract}
ABSTRAK
Lithium adalah salah satu mineral yang mempunyai permintaan yang paling tinggi dalam Revolusi Industri Keempat. Indonesia yang kekayaan alam nikelnya besar, ingin menjadi negara penghasil baterai. Oleh karena itu, diperlukan investigasi sumber bahan baku utama lainnya dalam produksi baterai. Sumber daya bahan baku utama baterai adalah Lithium. Penyelidikan litium sebagai sumber bahan baku di Indonesia telah dilakukan melalui tinjauan pustaka. Sumber daya alam litium ditemukan di air laut, Brine, mineral, dan tanah liat. Endapan yang mengandung Mineral Lithium terdapat di beberapa tempat di Indonesia dalam jumlah dan konsentrasi yang kecil. Sebagai negara yang dilalui cincin api, Indonesia memiliki banyak mata air panas dan Brine yang mengandung Lithium. Tanah liat yang mengandung litium ditemukan dalam bentuk slurry (brine dan lumpur tanah liat), seperti pada lumpur Bleduk Kuwu dan lumpur Sidoharjo. Bittern sebagai limbah industri garam memiliki potensi besar untuk dikembangkan sebagai sumber Lithium di Indonesia
\end{abstract}

Kata kunci: Lithium, Sumber Air Panas, Brine, Clay, Bittern

\begin{abstract}
Lithium is one of most demanding minerals in The Fourth Industrial Revolution. Indonesia whose large Nickel natural resources, wants to become a battery producing country. Therefore an investigation of other main raw material sources in battery production is needed. The main raw material resource for batteries is Lithium. The investigation of lithium as raw material resource in Indonesia has been carried out through a literature review. Lithium natural resources are found in sea water, Brine, minerals, and clay. Mineral Lithium containing deposits are found in several places in Indonesia in small amounts and concentrations. As a country through which the ring of fire passes, Indonesia has a lot of hot spring water and Brine containing Lithium. Clay containing lithium is found in the form of slurry (brine and clay mud), such as in the Bleduk Kuwu mud and the Sidoharjo mud. Bittern as a waste of salt industries has great potential to be developed as a source of Lithium in Indonesia
\end{abstract}

Keywords: Lithium, Hot Spring Water, Brine, Clay, Bittern 


\section{PENDAHULUAN}

Lithium adalah salah satu mineral tanah jarang (rare earth minerals) yang saat ini memiliki trens permintaan kenaikan tajam di era revolusi industry 4.0. Lithium mempunyai berbagai pemanfaatan didalam kehidupan sebagaimana disajikan dalam Gambar 1. Pemanfaatan Lithium sebagai energy storage / batteries mempunyai dua fungsi yaitu 1. untuk menjaga stabilitas pemanfaatan energi terbarukan yang pasokannya fluktuatif terhadap waktu dan 2. kendaraan / mobile equipment dengan alasan fleksibilitas dan emisi gas rumah kaca yang minimum. Penggunaan lithium yang semakin sentral ini membuat permintaan lithium dan harga lithium yang tinggi. Permintaan Lithium di tahun 2025 diprediksikan dapat menyentuh angka lima ratus ribu ton pertahun [1].

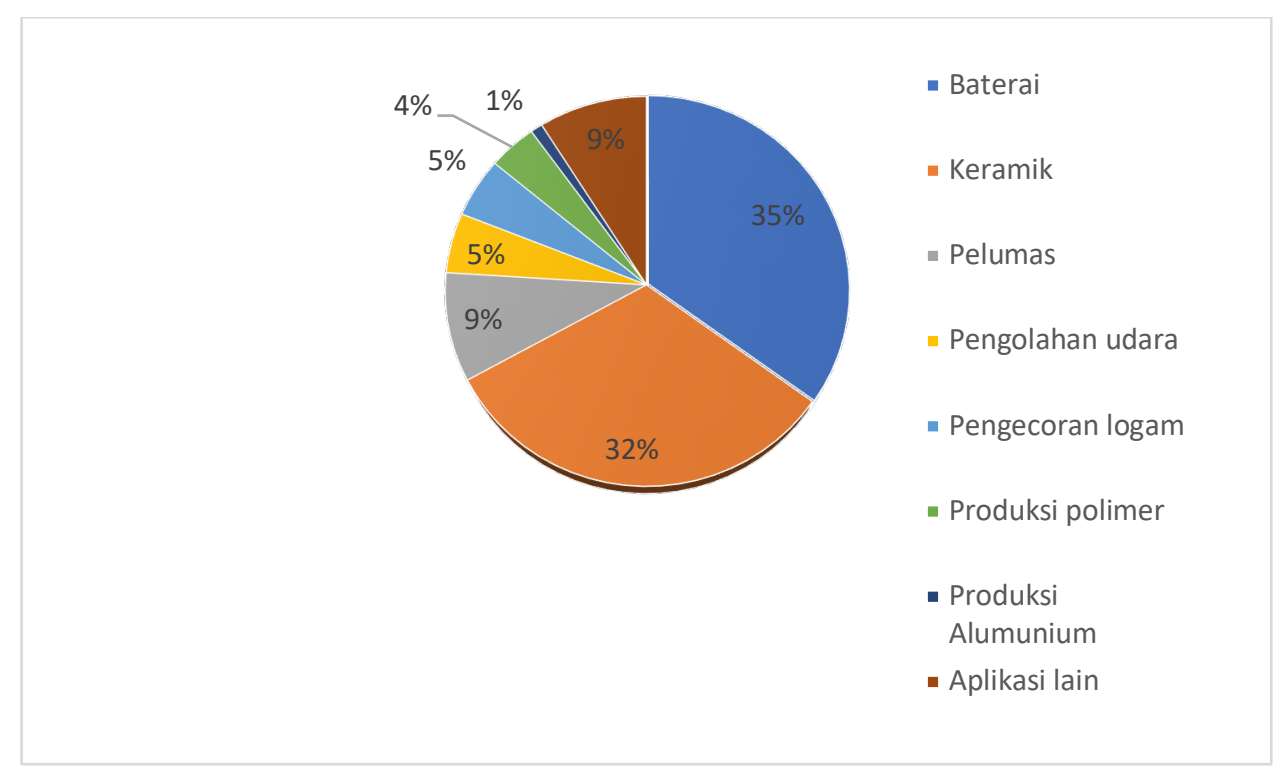

Gambar 1. Pemanfaatan lithium dalam kehidupan

Sumber: [2]

Sumber lithium di alam ditemukan di air laut, air asin (Brine), mineral, dan tanah liat (Clay) [3]. Masing-masing sumber lithium tersebut mempunyai karakteristik masing-masing sehingga teknologi proses yang digunakan berbeda dan produk teknologi recovery Lithium dalam bentuk senyawa yang berbeda. Senyawa-senyawa ini selanjutnya akan dipakai sebagai bahan baku industri lain. Proses yang dipakai untuk mengolah sumber daya alam Lithium dalam bentuk Brine, air laut dan sumber air panas (hotspring water) hampir sama. Lithium yang terkandung dalam Clay mempunyai proses tambahan ekstraksi dengan air sebelum akhirnya memakai teknologi yang sama dengan pengolahan lithium dalam brine. Berdasarkan hal tersebutlah maka Speir mengelompokan lithium yang terkandung didalam brine, seawater dan Clay dalam satu kelompok dalam peta pohon industri proses pengolahan lithium dari sumber daya alam yang disajikan dalam Gambar 2 . 


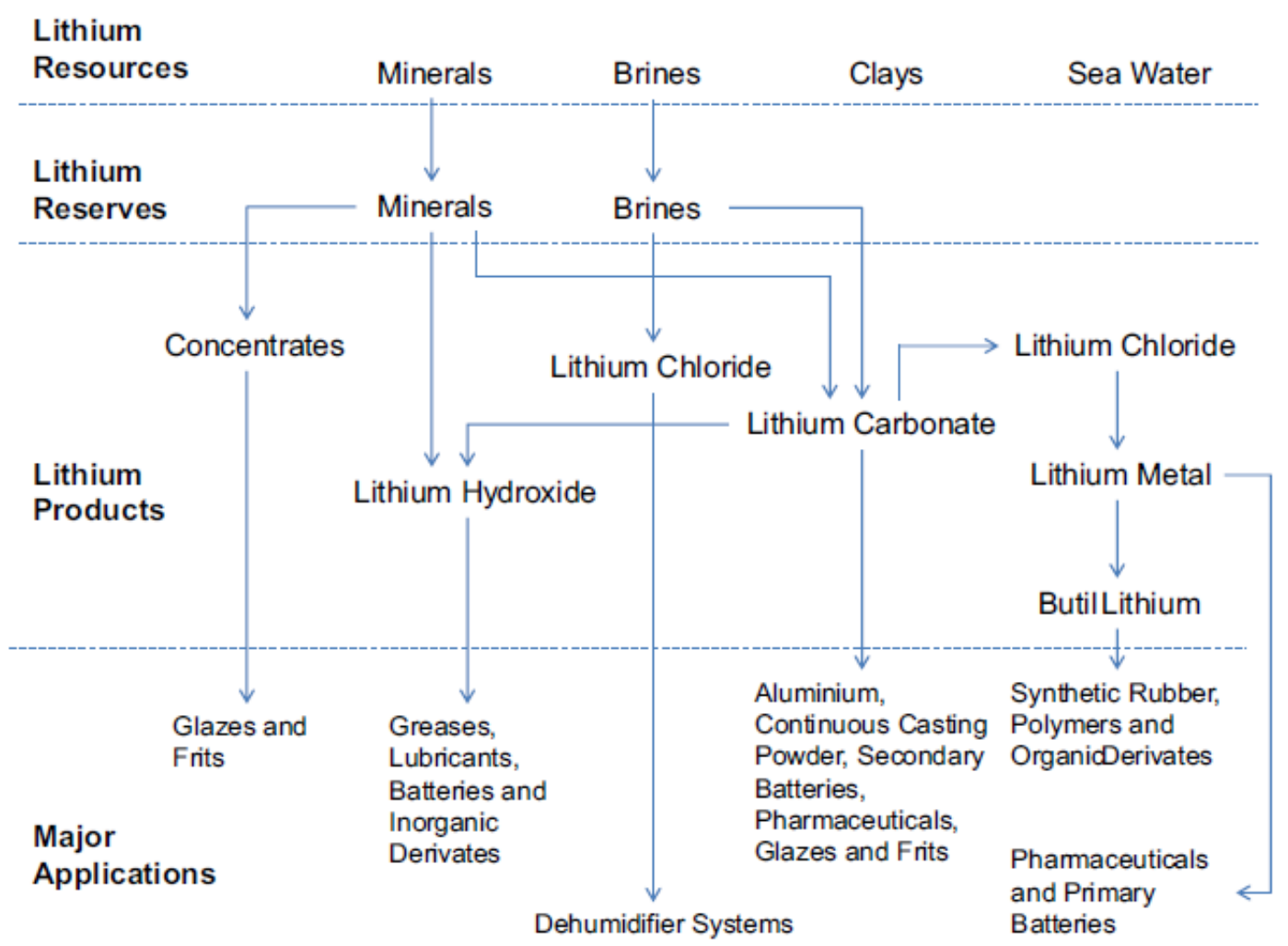

Gambar 2. Peta pohon industri pemanfaatan sumber daya alam lithium

Sumber: [3]

Cadangan Lithium Dunia yang telah diketahui sebesar 14 juta ton dengan negara penghasil utama berturut-turut Chile, China, Argentina, dan Australia. Penambangan terbesar Lithium masih dihasilkan dari sumber tambang berbentuk brine.

Tabel 1. Cadangan lithium dunia

\begin{tabular}{lll}
\hline No. & Negara & Cadangan (Ton) \\
\hline 1 & Chile & 7.500 .000 \\
\hline 2 & China & 3.200 .000 \\
\hline 3 & Argentina & 2.000 .000 \\
\hline 4 & Australia & 1.600 .000 \\
\hline 5 & Portugal & 60.000 \\
\hline 6 & Brazil & 48.000 \\
\hline 8 & USA & 38.000 \\
\hline \multicolumn{2}{l}{ Total Cadangan Lithium Dunia } \\
\hline Sumber: [4]
\end{tabular}

Walaupun Indonesia tidak tercantum sebagai Negara yang mempunyai cadangan Lithium di Indonesia tetapi empat jenis sumber daya alam yang mengandung Lithium terdapat di Indonesia. Tidak tercatatnya Indonesia sebagai negara yang mempunyai kandungan deposite Lithium karena tidak adanya penelitian yang mendalam yang didedikasikan untuk menghitung deposite Lithium di bumi Indonesia walaupun ke empat jenis sumber Lithium diatas ditemukan di Indonesia. Karena hal itulah maka kajian ini dilakukan dengan tujuan mengetahui jenis deposit Lithium yang ditemukan di Indonesia, memperkirakan besarannya. Studi ini sangat bermanfaat untuk penentuan pengembangan 
jenis proses produksi yang cocok dikembangkan di Indonesia disesuaikan dengan jenis deposit lithium di Indonesia.

\section{METODOLOGI}

Penelitian merupakan penelitian studi literatur dengan menelaah jurnal, proseding, patent yang berisi bahasan yang berhubungan dengan sumber daya alam di Indonesia yang mengandung Lithium.

\section{HASIL DAN PEMBAHASAN}

\subsection{Sumber Daya Alam Lithium dalam Bentuk Batuan Mineral}

Batuan mineral yang mengandung Lithium ditemukan dalam bentuk graphite, tanah laterit-saprolit, dan $\alpha$-spodumen. Batuan ini ditemukan dibeberapa tempat mulai dari Sulawesi selatan [5], Sulawesi tengah [6], Kalimantan [8], dan Jawa tengah [7]. Lithium dalam konsentrasi yang tinggi sampai dengan 5\% dan layak ditambang ditemukan diMekongga, Samaturu, Kolaka, sulawesi selatan dengan luas areal $11 \mathrm{Ha}$ dan kedalaman sampai 13 meter. Sumber Batuan mineral lain mengandung konsentrasi lithium kecil dengan volume deposite yang tidak diketahui. Pengambilan Lithium dari batuan mineral melalui serangkaian proses mulai dari pengayaan yang melibatkan sejumlah unit pemisahan secara fisik dilanjutkan dengan proses piromethalurgi dan atau hydromethalurgi.

Tabel 2. Deposit mineral lithium di Indonesia

\begin{tabular}{|c|c|c|c|c|c|}
\hline No. & Mineral & Areal Deposit & $\begin{array}{c}\mathbf{L i} \\
\text { Konsentrasi }\end{array}$ & Kapasitas & Pustaka \\
\hline 1. & Graphite & $\begin{array}{l}\text { Mekongga, Samaturu, Kolaka, } \\
\text { Sulawesi Selatan }\end{array}$ & $5 \%$ & $\begin{array}{c}11 \mathrm{Ha}, \\
13 \mathrm{~m} \\
\text { Thickness }\end{array}$ & {$[5]$} \\
\hline 2. & tanah laterit dan saprolit & $\begin{array}{l}\text { masama dan pagimana, } \\
\text { Banggai, sulawesi tengah }\end{array}$ & 3-38 ppm & $\begin{array}{l}\text { Thickness } \\
5 \mathrm{~m}\end{array}$ & [6] \\
\hline 3. & $\alpha$-spodumen & Kebumen,jawatengah & $3,14 \mathrm{ppm}$ & & [7] \\
\hline 4. & $\alpha$ spodume (LiAlSi2O6) & Kalimantan & $3,09 \mathrm{ppm}$ & & [8] \\
\hline
\end{tabular}

\subsection{Sumber Daya Alam Lithium dalam Bentuk Clay}

Salah satu sumber deposit Lithium berbentuk clay yang ada diIndonesia adalah Lumpur Sidoharjo (LuSi) atau lumpur Lapindo [9] [10]. Lumpur Sidoharjo merupakan menurut Klasifikasi sumber Lithium oleh J. Speir adalah Brine dan Clay karena baik air maupun padatan lumpur Sidoharja mengandung Lithium. Volume luapan lumpur Sidoharjo mencapai $180.000 \mathrm{~m} 3 /$ hari dan diperkirakan akan berlangsung selama ratusan tahun [11]. Sedangkan Kandungan Lithium Cairan lumpur Sidoharjo mengandung Lithium 5,81 - 15,985 ppm [12] [13]. Kandungan Lithium didalam padatan lumpur Sidoharjo belum ada yang meneliti.

Sumber Deposit Lithium lain dalam bentuk Clay ditemui di Bledug kuwu. Baik Lusi maupun Bledug kuwu tergolong mud volcono. Lithium yang berada dalam cairan dan padatan Clay (montmorillonite) saling berinteraksi adsorpsi desorpsi sehingga konsentrasi keduanya selalu berubah tergantung dengan banyaknya air dan temperatur. Sehinga Beberapa peneliti menghasilkan konsentrasi yang berbeda ketika penelitian dijalankan pada waktu yang berbeda. Rohmah dan Lalasari menyatakan bahwa konsentrasi Lithiumnya sampai $41 \mathrm{ppm}$ dan terjadi proses desorpsi oleh air pada temperatur 25- 45 [14],[15]. Sumarno dan Sulistiyono menyampaikan bahwa cairan brine bleduk kuwu mengandung Lithium 138,64 ppm sedangkan padatan lumpurnya konsentrasi Lithiumnya sampai 400 ppm [16],[17]. Fenomena adsorpsi desorpsi Lithium ini membuat kandungan deposit Lithium berbentuk 
Clay bersifat dinamis sehingga dalam penentuan besarannya diperlukan studi mendalam tentang kinetika kesetimbangan Lithium dalam kedua fase sebagai fungsi temperatur.

Tabel 3. Deposit lithium dalam bentuk Clay di Indonesia

\begin{tabular}{lllccc}
\hline \multirow{2}{*}{ No. } & \multirow{2}{*}{ Jenis Deposit } & \multicolumn{1}{c}{ Areal Deposite } & \multicolumn{2}{c}{ Li Konsentrasi (ppm) } & \multirow{2}{*}{ Literature } \\
\cline { 4 - 5 } & Clay-Brine & $\begin{array}{l}\text { Lumpur Sidoharjo } \\
\text { (LUSI) }\end{array}$ & $5,81-15,985$ & Clay & \\
\hline 2 & Clay-Brine & $\begin{array}{l}\text { Bledug kuwu, } \\
\text { grobogan, jawa tengah }\end{array}$ & 138,64 & 400 & {$[16],[17]$} \\
\hline
\end{tabular}

\subsection{Sumber Daya Alam Lithium dalam Bentuk Brine}

Sumber Lithium dalam Bentuk Brine diindonesia ditemukan dalam bentuk Bittern atau Larutan Induk penggaraman, Sumber air panas (hot spring Water), dan Brine cairan kondensat pembangkit listrik tenaga panas bumi. Karena Indonesia dilalui oleh Ring of Fire maka banyak ditemui hot spring yang mengandung Lithium mulai dari 0,025-17,27 ppm. Tidak semua sumber lithium ini diketahui debitnya sehingga tidak bisa dilakukan perhitungan kapasitas depositnya secara keseluruhan. Air kondensat pembangkit listrik geothermal PLTP Dieng mengandung Lithium sangat tinggi 77,31-99,4 ppm. Data ini mengindikasikan perlunya dilakukan penelitian lebih lanjut terhadap air kondensat PLTP sejenis diseluruh Indonesia. Brine yang berbentuk danau air asin dengan konsentrasi garam yang sangat tinggi tidak ditemukan di Indonesia tetapi Brine dalam bentuk Bittern yang belum termanfaatkan ditemuai pada setiap industri garam di Indonesia. Konsentrasi Lithium dalam Bittern ini sangat bervariasi dilapangan tergantung dari metode produsen garam dapur menghasilkan produknya. Data deposit Lithium selengkapnya dalam bentuk Brine disajikan di Tabel 4.

Teknologi recovery lithium dalam bentuk brine yang berkembang sekarang adalah selektif adsorbent, Elektro dialysis dan membrane. Melihat karakteristik sumber Brine di Indonesia yang kapasitasnya tidak besar dan tersebar maka teknologi yang paling tepat dikembangkan dan diaplikasikan di Indonesia adalah selektif adsorbent. Selektif Adsorbent Lithium Mangan Okside (LMO) dapat menjerap Lithium dalam konsentrasi rendah dibawah 1 ppm seperti pada air laut dan beberapa hot spring water sampai seratusan ppm pada brine.

Tabel 4. Deposit lithium dalam bentuk Brine di Indonesia

\begin{tabular}{lllccc}
\hline No. & \multicolumn{1}{c}{ Jenis Deposit } & \multicolumn{1}{c}{ Areal } & $\begin{array}{c}\text { Li Konsentrasi } \\
(\mathbf{P P M})\end{array}$ & Debit (Liter/detik) & Pustaka \\
\hline 1 & Bittern & All Indonesia & 1100 & 0,232865 & {$[18],[19]$} \\
\hline 2 & hot spring water & kawah Domas & $0,1-0,2$ & & {$[20]$} \\
\hline 3 & hot spring water & Ciater & Batugede 5 & 0,84 & {$[20]$} \\
\hline 4 & hot spring water & Batugede7 & 1,88 & $0,1-1,5$ & {$[20]$} \\
\hline 5 & hot spring water & Batukapur1 & 5,4 & $0,1-1,5$ & {$[20]$} \\
\hline 6 & hot spring water & Batukapur2 & 7,03 & 3,00 & {$[21]$} \\
\hline 7 & hot spring water & Ciracas1 & 3,44 & 3,00 & {$[21]$} \\
\hline 8 & hot spring water & Ciracas2 & 8,8 & 1,00 & {$[21]$} \\
\hline 9 & hot spring water & Maribaya1 & 1,73 & 5,00 & {$[21]$} \\
\hline 10 & hot spring water & Maribaya2 & 0,025 & 5,00 & {$[21]$} \\
\hline 11 & hot spring water & Kancah1 & 0,94 & 10,00 & {$[21]$} \\
\hline 12 & hot spring water & Kancah2 & 0,63 & 10,00 & {$[20]$} \\
\hline 13 & hot spring water & Cimanggu1 & 0,16 & 1,00 & {$[20]$} \\
\hline 14 & hot spring water & Cimanggu3 & 0,31 & 1,00 & {$[20]$} \\
\hline 15 & hot spring water & Ciseeng,Bogor & 17,27 & & {$[20]$} \\
\hline 16 & hot spring water & & & {$[22]$} \\
\hline
\end{tabular}




\begin{tabular}{|c|c|c|c|c|c|}
\hline No. & Jenis Deposit & Areal & $\begin{array}{l}\text { Li Konsentrasi } \\
\text { (PPM) }\end{array}$ & Debit (Liter/detik) & Pustaka \\
\hline 17 & hot spring water & Tangkuban Perahu & $0.3-8.8$ & & [23] \\
\hline$\overline{18}$ & hot spring water & $\begin{array}{l}\text { Tasin,Lawu, jawa } \\
\text { tengah }\end{array}$ & 0,022 & & [21] \\
\hline 19 & hot spring water & Pancuran, G Slamet & 0,07 & & [21] \\
\hline 20 & hot spring water & Ciawi & $0,49-0,53$ & & [21] \\
\hline 21 & hot spring water & Cipanas & $0,10-0,12$ & & [21] \\
\hline 22 & hot spring water & Kanandede,Limbong & $0,4-8,3$ & & [24] \\
\hline 23 & hot spring water & $\begin{array}{l}\text { Padusan, G Arjuna- } \\
\text { Welirang }\end{array}$ & $0,13-0,17$ & & [21] \\
\hline 24 & hot spring water & $\begin{array}{l}\text { Songgoriti, G Arjuna- } \\
\text { Welirang }\end{array}$ & $0,14-0,17$ & & [21] \\
\hline 25 & hot spring water & G Lawu & $0,01-11,06$ & & {$[21]$} \\
\hline 26 & hot spring water & Pangalengan & $0,05-0,06$ & & [21] \\
\hline 27 & hot spring water & Pohuwato,Sulawesi & $10-12$ & & [24] \\
\hline 28 & hot spring water & $\begin{array}{l}\text { Cileungsing, } \\
\text { Tampomas }\end{array}$ & 1,3 & & {$[25]$} \\
\hline 29 & hot spring water & Cilendre,Tampomas & 0,9 & & [25] \\
\hline 30 & hot spring water & Congeang,Tampomas & 0,4 & & [25] \\
\hline 31 & hot spring water & Ciuyah,Tampomas & 21,3 & & [25] \\
\hline 32 & hot spring water & Cihaseum,Tampomas & 0,8 & & [25] \\
\hline 33 & Brine from Silencer PLTP & Cibitung, Tampomas & 0,2 & & [25] \\
\hline 34 & Mata Air Panas & Cituruban, Tampomas & 0,8 & & [25] \\
\hline 35 & hot spring water & $\begin{array}{l}\text { Cihaseum } \\
\text { kolot,Tampomas }\end{array}$ & 0,9 & & [25] \\
\hline 36 & hot spring water & Dieng & $0.01-0,88$ & & {$[26]$} \\
\hline 37 & Brine from Silencer PLTP & PLTP Dieng & $77,31-99,4$ & & [27] \\
\hline 38 & hot spring water & Cilayu & $1,78-2,23$ & & [21] \\
\hline 39 & hot spring water & Tanggeung- Cibungur & $<1.0$ & & [24] \\
\hline 40 & hot spring water & $\mathrm{Napu}$ & 0.7 & & [24] \\
\hline 41 & hot spring water & Toare & $<4.2$ & & [24] \\
\hline 42 & hot spring water & Parara-Pincara & 0.5 & & [24] \\
\hline 43 & hot spring water & Limbong & $0.4-8.3$ & & [24] \\
\hline 44 & hot spring water & Maranda & $0.2-3.7$ & & [24] \\
\hline 45 & hot spring water & Bituang & $7.0-11$ & & [24] \\
\hline 46 & hot spring water & Tambu & 5,9 & & [24] \\
\hline$\overline{47}$ & hot spring water & Dolok Marawa & $0.5-0.9$ & & [24] \\
\hline 48 & hot spring water & Lainea & $<0.75$ & & {$[24]$} \\
\hline 49 & hot spring water & Pohuwato & $10-12$ & & [24] \\
\hline 50 & hot spring water & Kamojang & $<0.8$ & & [28] \\
\hline 51 & hot spring water & Darajat & 1,4 & & [28] \\
\hline 52 & hot spring water & Salak & 12,4 & & [28] \\
\hline 53 & hot spring water & Wayang Windu & 33 & & [28] \\
\hline 54 & hot spring water & Gunung Ciremai & $<0.4$ & & [29] \\
\hline 55 & hot spring water & Cidanau, Banten & $<1.6$ & & [30] \\
\hline 56 & hot spring water & Malingping & $<0.3$ & & [24] \\
\hline 57 & hot spring water & Gunung Kaca & $2.0-2.4$ & & [24] \\
\hline 58 & hot spring water & Permis & 0.5 & & [24] \\
\hline$\overline{59}$ & hot spring water & $\begin{array}{l}\text { Gunung Botak, } \\
\text { Rajabasa }\end{array}$ & $2,8-75$ & & [31] \\
\hline 60 & hot spring water & Way merah Rajabasa & $0,10-0,13$ & & {$[31]$} \\
\hline$\overline{61}$ & hot spring water & Kunjir Rajabasa & 0,14 & & [31] \\
\hline 62 & hot spring water & Merpati Rajabasa & 1,3 & & [31] \\
\hline
\end{tabular}




\begin{tabular}{|c|c|c|c|c|c|}
\hline No. & Jenis Deposit & Areal & $\begin{array}{l}\text { Li Konsentrasi } \\
\text { (PPM) }\end{array}$ & Debit (Liter/detik) & Pustaka \\
\hline 63 & hot spring water & Kepahiang & $<0,8$ & & [24] \\
\hline 64 & hot spring water & Geureudong & 25,3 & & [24] \\
\hline 65 & hot spring water & Ulubelu & $1,2-2,3$ & & [32] \\
\hline 66 & hot spring water & Sibualbuali & $0.5-0.7$ & & [33] \\
\hline 67 & hot spring water & Donotasik & $4.4-7.4$ & & [33] \\
\hline 68 & hot spring water & Namora-I-Langit & $0,1-4.1$ & & [33] \\
\hline 69 & hot spring water & Silangkitang & $6.3-6.5$ & & [33] \\
\hline 70 & hot spring water & Pancubatu, Sumatra & 0,02 & & [34] \\
\hline 71 & hot spring water & Aek Nasia, Sumatra & 0,02 & & [34] \\
\hline 72 & hot spring water & Air Soda, Sumatra & 0,02 & & [34] \\
\hline 73 & hot spring water & Hutapea, Sumatra & 0,17 & & [34] \\
\hline 74 & hot spring water & Ria-Ria, Sumatra & 0,65 & & [34] \\
\hline 75 & hot spring water & Partali Jalu, Sumatra & 0,42 & & [34] \\
\hline 76 & hot spring water & Hutabarat, Sumatra & 0,74 & & [34] \\
\hline 77 & hot spring water & Sitompul, Sumatra & 0,73 & & [34] \\
\hline 78 & hot spring water & Pansur Napitu & 0,47 & & [34] \\
\hline 79 & hot spring water & Akbid, Sumatra & 0,67 & & [34] \\
\hline 80 & hot spring water & Panabungan, Sumatra & 0,52 & & [34] \\
\hline 81 & hot spring water & Pionar, Sumatra & 0,47 & & [34] \\
\hline 82 & hot spring water & Sisordak, Sumatra & 0,49 & & [34] \\
\hline 83 & hot spring water & Butar, Sumatra & 0,44 & & [34] \\
\hline 84 & hot spring water & Mataloko & $0,01-0,04$ & & [35] \\
\hline 85 & hot spring water & Songa-Wayaua & $0.13-8.60$ & & [24] \\
\hline
\end{tabular}

\subsection{Kapasitas Sumber Daya Alam Lithium Indonesia}

Kapasitas Sumber daya lithium Indonesia di hitung berdasarkan sumber daya yang telah diketahui konsentrasi dan Debit atau besarannya. Berdasarkan perhitungan yang disajikan pada Tabel 4. kapasitas lithium yang bisa dihasilkan oleh Indonesia adalah 14.105 ton per tahun. Sumber daya Lithium yang besar sudah cukup besar bila dibandingkan dengan jadangan Lithium USA yang 38.000 ton karena kapasitas Sumber daya alam Indonesia disajikan dalam satuan pertahun. Berdasarkan data ini maka dimasa yang akan datang terdapat kemungkinan Indonesia menjadi penghasil Lithium yang diperhitungkan bila dapat mengoptimalkan sumber daya lithium yang tersedia dibumi Nusantara dalam bentuk Brine, Clay dan air laut.

Tabel 4. Kapasitas deposit lithium Indonesia

\begin{tabular}{lllccc}
\hline No & Jenis Deposit & Areal & $\begin{array}{c}\text { Li Konsentrasi } \\
\text { (PPM) }\end{array}$ & Debit (Liter/detik) & $\begin{array}{c}\text { Capasitas Li } \\
\text { (tons/tahun) }\end{array}$ \\
\hline 1 & Bittern & All Indonesia & 1100 & 0,232865 & 7967 \\
\hline 2 & hot spring water & Ciater & 0,84 & 50,00 & 1306 \\
\hline 3 & hot spring water & Batukapur2 & 7,03 & 3,00 & 656 \\
\hline 4 & hot spring water & Batukapur1 & 5,4 & 3,00 & 504 \\
\hline 5 & Brine from Silencer PLTP & PLTP Dieng & 99,4 & 0,126972 & 393 \\
\hline 6 & hot spring water & Kancah1 & 0,94 & 10,00 & 292 \\
\hline 8 & hot spring water & Ciracas2 & 8,8 & 1,00 & 274 \\
\hline 9 & hot spring water & Maribaya1 & 1,73 & 5,00 & 269 \\
\hline 10 & hot spring water & Kancah2 & 0,63 & 10,00 & 196 \\
\hline 11 & hot spring water & Batugede7 & 3,13 & 1,50 & 146 \\
\hline & hot spring water & Ciracas1 & 3,44 & 1,00 & 107 \\
\hline
\end{tabular}




\begin{tabular}{llllll}
\hline 12 & hot spring water & Batugede 5 & 0,44 & 1,50 & 21 \\
\hline 13 & hot spring water & Cimanggu3 & 0,31 & 1,00 & 10 \\
\hline 14 & hot spring water & Cimanggu1 & 0,16 & 1,00 & 5 \\
\hline 15 & hot spring water & Maribaya2 & 0,025 & 5,00 & 4 \\
\hline Kapasitas Li Total (Tons/tahun) & & & & 12149 \\
\hline
\end{tabular}

\section{KESIMPULAN}

Deposit litium di Indonesia kecil hanya cukup untuk kebutuhan domestik. Brine merupakan deposit potensial lithium, teknologi berbasis adsorpsi selektif merupakan teknologi paling menjanjikan untuk recovery lithium di Indonesia. Penelitian lebih lanjut untuk menghasilkan adsorben LMO yang membutuhkan selektivitas, kapasitas dan daya tahan yang tinggi.

\section{UCAPAN TERIMA KASIH}

Terima kasih kepada Institut Teknologi Nasional Bandung Indonesia, yang telah dimembiayai penelitian ini melalui lembaga penelitian dan pengabdian kepada masyarakat.

\section{DAFTAR PUSTAKA}

[1] Azpilcueta, D.C. , Leon, S. H, Cisternas, L.A, (2020)." Current and Future Global Lithium Production Till 2025", The Open Chemical Engineering Journal, 14, pp 36-51.

[2] Swain,B., (2017). "Recovery and Recycling of Lithium: A review", Separation and Purification Tecnology Journal, 172, pp.388-403

[3] Speir, J., Contestabile, M., Houari, Y., Gross, R., (2014). "The Future of Lithium Availability for electric Vehicle Batteries", Renewable and Sustainable Energy Reviews 35, pp 183-193.

[4] Luis, A, Gil-Alanan, Monge, M, (2019). "Lithium: Production and Eastimated Consumption. Evidence of Persistence", Resources Policy 60, pp 198-202.

[5] Florena,F.F.,(2016)." Floatability Study of Graphite ore from Southeast Sulawesi (Indonesia)", AIP Conference Proceeding 1712, 050005

[6] Kisman, (2014).” Prospeksi Unsur Tanah Jarang / Rare Earth Elements (REE) di Kabupaten Banggai Provinsi Sulawesi Tengah", Laporan Pusat Sumber Daya Mineral, Batubara dan Panas Bumi, Badan Geologi

[7] Natasha,N.C., (2018)." Ekstraksi Lithium dari $\beta$ - Spodumen Hasil Dekomposisi Batuan Sekismika Indonesia Menggunakan Aditif Natrium Sulfat”, Metalurgi, 2, pp 69-78.

[8] Suharyanto,A. ( 2019)." Decomposition of Spodumene Mineral in Granitic Rocks from South Kalimantan - Indonesia bu Potassium Sulphate", IOP Conf Series: Material Science and Engineering 541, 012044

[9] Supriyana, E., (2019)." Gravity data of porong regions, Sidoarjo in the Interpretation geology Structure and deformation of Subsurface", IOP Conf. Series:Earth and Environmental Science 311.

[10] R. Wirosoedarmo, R.,(2020)." Effect of Pyrolysis Temperature on Biochar to Reduce Cadmium Concentration in Impacted Lapindo Mudsoil in Sidoarjo, East Java", Poll Res, 39 (2), pp 442449.

[11] Taufik,M., , (2009). " Digital Elevation Model (DEM) Aster untuk Menghitung Volume Lumpur Lapindo", Geoid, 04 No.2, pp 166-170.

[12] Noerochim,L., (2016). " Recovery of Lithium from Geothermal Fluid at Lumpur Sidoarjo by Adsorption Method", J.Eng Technol.Sci, 48 No2, pp. 200-206. 
salafudin

[13] Noerochim,L., (2016). " Lithium Manganese Oxide nanoparticles synthesized by hydrothermal method as adsorbent of Lithium Recovery Process from geothermal Fluid of Lumpur Sidoarjo", AIP Conference Proceeding 1725,020054

[14] Rohmah, M., (2018). " Lithium Recovery from Bledug Kuwu Mud Volcano Using Water Leaching Method", IEEE International Conference on Innovative Research and Development.

[15] Lalasari, L.H.,(2019). " Effect of Leaching Temperatur on Lithium recovery from LiMontmorillonite (Bledug Kuwu's Mud)", The $2^{\text {nd }}$ Mineral Processing and Technology International Conference.

[16] Sumarno, (2012). "Recovery Garam Lithium dari Air Asin (Brine) dengan Metoda Presipitasi", Teknik, 33(2).

[17] Sulistiyono, E., (2018). "Study of Lithium Extraction from Brine Water, Bledug Kuwu, Indonesia by the Precipitation Series of Oxalic Acid and Carbonate Sodium", AIP Conference Proceeding 1964, 020007.

[18] Manao, R.D., (2012). " Recovery Garam Lithium pada Air Tua (bittern) dengan Metode Presipitasi”, Jurnal Teknologi Kimia dan Industri, 1, 292-297.

[19] Apriani, M., (2018). " Physicochemical properties of Sea Water and Bittern in Indonesia Quality Improvement and Potential Resources Utilization for Marine Environmental Sustainability", Journal of Ecological Engineering, 19, 1-10.

[20] Boedihardi, R.M., (1987). " Interpretation of Tangkuban Perahu Geophysical Data (West Java Indonesia)", Project for Diploma in Geothermal Energy Technology, Geothermal Institute, University of Auckland.

[21] Purnomo, B.J. dan Pichler, T., (2014). " Geothermal systems on the island of Java, Indonesia", Journal of Volcanology and Geothermal Research 285, 47-59.

[22] Lalasari, L.H., Andriyah, L., Arini, T., Sulistiyono, E., Prasetyo, E., Firdiyono, Natasha, N.C., (2020). "Litihium Extraction from Brine Water Tirtasanita Bogor, Indonesia by Evaporation Method", Journal of Physics: Conference Series, 1450, 012013.

[23] Nasution, A., Kartadinata, M. N., Kobayashi, T., Siregar, D., Sutaningsih, E., Hadisantono, R., Kadarstia, E., (2004). " Geology Age Dating, and Geochemistry of the Tangkuban Parahu Geothermal Area, West Java, Indonesia", Journal of the Geothermal Research Society of Japan, 26(3), 285-303.

[24] PSDMBP (Pusat Sumber Daya Mineral, Batubara, dan Panas Bumi), Badan Geologi., (2017). ” Potensi Panas bumi Indonesia", Jakarta: Direktorat Jendral EBTKE.

[25] Rahayudin, Y., Kashiwaya, K., Susmanto, A., Tada, Y., Iskandar, I., and Koike, K., (2018).” Estimation of Fluid-rock Interaction Process and Recharge Area of the Tampomas Geothermal Field, West Java, Indonesia by Water Chemistry", Proceedings 43rd Workshop on Geothermal Reservoir Engineering Stanford University.

[26] Ramadhan, Y., Channel, K., and Herdianita, N. R., (2013). "Hotwater Geochemistry for Interpreting The Condition of Geothermal Reservoir, Dieng Plateau Case, Banjarnegara Wonosobo Regency, Central Java.Indonesian”, Journal of Geology, 8(2), 89- 96.

[27] Suprapto, S.M., (2020). "Potensi Kandungan Unsur Kimia Ekonomis pada Larutan Panas Bumi dengan Studi Kasus di PLTP Dieng, Kabupaten Wonosobo dan Kabupaten BanjarNegara", Buletin Sumber Daya Geologi, 15(2), 89-100.

[28] Mahon, T., Harvey, C., and Crosby, D., (2000). " The Chemistry of Geothermal Fluids in Indonesia and Their Relationship to Water and Vapour Dominated Systems", Proceeding World Geothermal Congress, 1389-1394.

[29] Herdianita, N. R., Julinawati, T., and Amorita, I. E.,(2010). " Hydrogeochemistry of Thermal Water from Surface Manifestation at Gunung Ciremai and Its Surrounding, Cirebon, West Java Indonesia", Proceeding World Geothermal Congress.

[30] Alam, B. Y. C. S., Itoi, R., Taguchi, S., and Yamashiro, R., (2014). "Hydrogeochemical Characterization and the Origin of Hot Springs in the Cidanau Geothermal Field, West Java, Indonesia", Proceeding Thirty-Ninth Workshop on Geothermal Reservoir Engineering Stanford University. 
[31] Mussofan, W., Powell, T., Sutrisno, L., and Sihotang, M. A. (2015). "Geochemistry Model of Chloride Springs Origin near Sea Coastal Area: Case Study from Rajabasa Geothermal Field", Proceeding World Geothermal Congress.

[32] Sunaryo, Hantono, D., Ganda, S., and Nugroho., (1993). "Exploration Result of the Ulubelu Geothermal Prospect, South Sumatra, Indonesia", Proceeding 15th NZ Geothermal Workshop.

[33] Gunderson, R. P., Dobson, P. F., Sharp, W. D., Pudjianto, R., and Hasibuan, A., (1995).," Geology and Thermal Features of the Sarulla Contract Area, North Sumatra, Indonesia", Proceeding World Geothermal Congress.

[34] Nukman, M. and Hochstein, M. P., (2018). "The Sipoholon Geothermal Field and Adjacent Geothermal System along the North-Central Sumatra Fault Belt, Indonesia: Review on Geochemisty, Ttectonics, and Natural Heat Loss", Journal of Asian Earth Sciences 170, 316-328.

[35] Dahlan, Eddy, M., Anna, Y., (2011). "Monitoring Sumur-Sumur Eksplorasi Lapangan Panasbumi Mataloko, Provinsi Nusa Tenggara Timur", Proceeding Hasil Kegiatan Pusat Sumber Daya Geologi Tahun 2011. 